\title{
Editorial
}

\section{El inédito contexto de la migración internacional en tiempos de COVID-19}

Sin duda alguna, en los próximos años unos de los tópicos que marcará la agenda de la investigación en migración internacional es lo relacionado con la impronta del COVID-19 en los desplazamientos humanos desde el análisis de coyuntura e historia del presente. Seguirán generándose sesudos análisis en las recurrentes aristas como lo son migración desarrollo y políticas públicas; redes sociales; fuga de cerebros; aspectos psicosociales de la migración; migración y género; el impacto de las remesas; derechos humanos de los migrantes, y los cada vez más socorridos temas del migración y medio ambiente, y migración y salud. Las proverbiales consideraciones macro, meso y micro analíticas que recogen las estructuras de corte económico-político, las deliberaciones familiares y de la industria de la migración, así como las profundidades volitivas, subjetivas, de agencia, redes, de permanencia, estatus y culturales que generan los flujos internacionales tienen y tendrán mucha atención epistemológica, ontológica y metodológica. Los flujos humanos generados por los avatares del medio ambiente, como son el cambio climático, sequías, tsunamis, terremotos, erupciones volcánicas, inundaciones, incendios, aunque fueron muy numerosas en épocas pretéritas, algunas de ellas se han recrudecido con virulencia en tiempos contemporáneos. La pandemia de COVID es una de ellas, que ha marcado un hito en la migración internacional. Ningún evento en los últimos siglos había logrado frenar de tajo los flujos internacionales como lo ha sido esta pandemia.

El fenómeno de la globalización del mundo contemporáneo ha propiciado profundos cambios que han incidido de manera superlativa en el orden internacional. Tales efectos se manifiestan en los ámbitos económico, cultural, político, las relaciones internacionales, las relaciones humanas. En este contexto, la globalización enlaza de manera ineluctable las economías y las sociedades y estimula la migración internacional [1]. El siglo XXI ha sido una etapa de gran movilidad, esta mantiene enormes recursos sociales fluyendo local, regional y globalmente. El espacio vital del individuo está en un contexto de permanente fluctuación. En esta era de demasiada movilidad un número cada vez mayor de migrantes transfronterizos esté emergiendo de nuestra sociedad [2]. Por ende, la característica cardinal de las actuales migraciones es su carácter global, involucrando a una mayor cantidad de naciones y regiones lo que adopta mayores rasgos de complejidad en sus causas y corolarios. La extensión global de las migraciones debe ser concebida no exclusivamente como el acrecentamiento de individuos trasnfronterizos, o de la paulatina incorporación de más países a los circuitos migratorios internacionales, sino también como la ramificación de las modalidades, motivaciones, tipologías, temporalidades migratorias [3]. Y también de las consecuencias. No debemos pasar por alto que en las sociedades actuales, los flujos migratorios han tenido un papel protagónico en la generación de cambios sociales de gran transcendencia, los impactos de los desplazamientos contemporáneos en los países de origen y destino han operado profundas transformaciones en las estructuras y organizaciones sociales, culturales, políticas, económicas [4]. Por ello, la migración internacional es una válvula de escape no solo en los aspectos económicos donde se alivian y procuran bienes de subsistencia, ingresos mayores, posibilidades en inversión productiva, educación y salud. Sino también es un ritual de paso donde se articulan elementos simbólicos de estatus, prestigio, gasto conspicuo, presencia comunitaria. Dicho esto, la migración internacional genera no solo solvencia económica sino consecuencias en la salud emocional por todos los impactos que genera el fenómeno a nivel regional, local, familiar e individual.

Además del impacto del COVID-19 en la salud física y mental de la población, se debe contemplar investigar afondo desde una perspectiva multidisciplinaria los efectos psicosociales generados por la pandemia en la migración internacional. El cierre de fronteras, la incertidumbre laboral, el redimensionamiento de la vida transnacional, la interrupción de los circuitos de retorno migrante, la disminución de las remesas económicas y sociales, los enfermos o muertes de familiares en el extranjero sin poder asistirlos y estar presentes en el duelo, el cierre de empresas migrantes, el desempleo, la falta de políticas públicas para atender al migrante ante tal zozobra, abrirán una agenda de investigación inédita y muy pertinente en los próximos años en el fenómeno de la migración internacional. Los grandes desafíos teórico-metodológicos para asirnos de tal conocimiento exigirán tenacidad, creatividad y años de ardua labor 
académica e intelectual. La pandemia ha abierto un escenario teórico y empírico de gran envergadura en los estudios migratorios. Flujos, circuitos, sistemas migratorios, índices, efectos en la salud física y emocional, el transnacionalismo, las economías, las identidades, las relaciones humanas, las familias, los derechos humanos, las políticas públicas, las políticas migratorias, el papel de las organizaciones no gubernamentales, de los Estados, se han visto transtocados y repercutirán en los años venideros. La complejidad del fenómeno migrante se ahonda con estas nuevas manifestaciones. Enfilemos las herramientas teóricas y metodológicas para tan extraordinario escenario.

Dr. Eduardo Fernández Guzmán

kutibirrin10@gmail.com

Doctor en Historia Moderna y Contemporánea

Universidad de Guanajuato, México

\section{Fuente de financiación}

Ninguna

\section{Conflicto de interés}

Ninguno

\section{Declaración de responsabilidad}

Se declara que los puntos de vista expresados son responsabilidad del editorialista

\section{Referencias}

1 Bravo G. Las migraciones internacionales y la seguridad multidimensional en tiempos de la globalización. Diálogo Andino - Revista de Historia, Geografía y Cultura Andina, 2015 (48):139-49.

2 Chan WW. A Double-Edged Sword: Mobility and Entrepreneurship. En: Chan Kwok-bun (ed.), International Handbook of Chinese Families, Springer. 2013. DOI 10.1007/978-1-4614-0266-4_7

3 Blanco C. Las migraciones contemporáneas, Madrid: Alianza Editorial, 2000.

4 Wabgou M. Migraciones internacionales y cambio social en las sociedades modernas. Revista Colombiana de Sociología, 2008 (31):93-113

DOI: https://doi.org/10.17533/udea.rfnsp.e346872

Esta obra se distribuye bajo una Licencia Creative Commons Atribución-NoComercial-Compartirlgual 4.0 Internacional

Más información: https://creativecommons.org/licenses/by-nc-sa/4.0/ 